\title{
O PARADOXO ENTRE A AUTONOMIA E A BENEFICÊNCIA NAS QUESTÕES DE SAÚDE: QUANDO O PODER ENCONTRA A VULNERABILIDADE
}

\author{
THE PARADOX BETWEEN AUTONOMY AND BENEFICENCE ON HEALTH \\ ISSUES: WHEN THE POWER MEETS THE VULNERABILITY
}

\section{RESUMO}

\author{
${ }^{1}$ Mônica Neves Aguiar da Silva
}

O trabalho busca apresentar uma proposta para equilibrar o respeito pela autonomia e o princípio da beneficência, de modo a afastar o paternalismo forte ou radical. Pela hipótese desenvolvida, a atuação médica muitas vezes é desvirtuada pela utilização do poder do conhecimento que o médico tem, em face da vulnerabilidade do paciente, aqui tratada como aquela decorrente do estado de doença, acrescida por circunstancias de natureza econômica e /ou social. Propõe-se que o equilíbrio pode ser alcançado com a aplicação da alteridade,, de modo a legitimar a intervenção para resguardar a autonomia sob a ótica do paternalismo brando de FEINBERG.

Palavras-chave: Autonomia, Beneficência, Vulnerabilidade, Poder

\begin{abstract}
The study aims to present a proposal to balance respect for autonomy and beneficence, in order to ward off strong paternalism. The hypothesis developed, the medical action is often distorted by the use of the power of knowledge that the doctor has, in the face of the patient's vulnerability, here treated as one due to the disease state, increased by circumstances of an economic and / or social. It is proposed that the balance can be achieved with the application of otherness, in order to legitimize the intervention to safeguard the autonomy from the perspective of soft paternalism Feinberg.
\end{abstract}

Keywords: Autonomy, Beneficence, Vulnerability, Power

\footnotetext{
${ }^{1}$ Doutora em Direito pela Pontifícia Universidade Católica de São Paulo - PUC, São Paulo-SP (Brasil). Professora da Universidade Federal da Bahia, UFBA, Salvador - BA (Brasil). E-mail: monicaaguiarpsi@gmail.com
} 


\section{INTRODUÇÃO}

Desde que Déscartes publicou o Discurso do Método (1637), tornou-se paradigma, no mundo científico, o método cartesiano de separar o objetivo do subjetivo na elaboração do conhecimento como único apto a gerar a descoberta da verdade:

Essa formulação, que atravessou os séculos, gerou forte impacto na academia, ao ponto de se prescrever como norma de boa técnica a escrita em terceira pessoa para caracterizar a natureza cientifica do estudo, em razão da necessidade de se reforçar o banimento da pessoalidade, vista como prejudicial ao -bem pensarll.

Como explica BYINGTON (2015, p.1) -Esse redutivismo impediu que o método científico incluísse também a função da ética do Ser e a relação dialética das funções estruturantes do pensamento com o sentimento, do subjetivo com o objetivo e do consciente com o inconscientell.

A percepção de não ser possível uma neutralidade do pesquisador, tem feito surgir diferentes vozes que contestam a certeza de que somente é científico o que excluir o subjetivo e passa-se a considerar, igualmente científico, o dar voz ao sujeito formulador do ensaio, desde que se perceba o lugar de onde se fala e, de modo transparente, se assuma o lugar da ausência de neutralidade, o qual deve ser sempre revelado, para que se aja de modo ético.

É nesse diapasão que passo a -vozificarll, nesta introdução, as razões da escolha do tema como forma de esclarecê-las e dar -ao relato um tom de sinceridade, de fidelidade, de testemunho vivo, que resulta em força de convencimento no processo argumentativoll (OLIVEIRA, 2014)

Chamou-me a atenção para o tema deste artigo, uma dissertação de mestrado na qual se sustentava, no exame do consentimento informado em questões de saúde, que a ocorrência do paternalismo se dá quando o princípio da beneficência é praticado com desrespeito à autonomia do paciente ${ }^{\mathrm{i}}$.

Nesse trabalho, MOREIRA (2015, p.40) afirmava:

O profissional de saúde, por ser o detentor do saber técnico, retira do paciente seu poder de autodeterminação, o impossibilitando de tomar decisões que refletirão diretamente sobre ele. O paciente é considerado um incapaz, que nada decide, obedecendo, sempre, aos mandamentos do médica. (sem grifos no original) 
Entendi que o tema deveria ser aprofundado, não somente como tratado pela autora, mas, em especial, para compreender as causas pelas quais a balança entre a autonomia e a beneficência pende, freqüentemente, para essa última, como se verá no curso deste trabalho.

Assim, percebi imperioso começar por esquadrinhar esses motivos para então confirmar, ou não, a hipótese de que não se trata apenas de uma colisão entre a autonomia e beneficência, mas também, entre o poder técnico atribuído ao médico e/ou ao pesquisador e a vulnerabilidade do paciente ou participante da pesquisa.

Dito de outro modo, percebi tratar-se de uma posição quadrangular, a qual passo a denominar de quatérnio bioético, no qual, horizontalmente, encontram-se a autonomia do paciente e/ou participante da pesquisa e a beneficência enquanto princípio ao qual o médico promete cumprir e, perpendicularmente, o poder técnico do expert e/ou pesquisador e a vulnerabilidade.

\section{QUATÉRNIO BIOÉTICO}

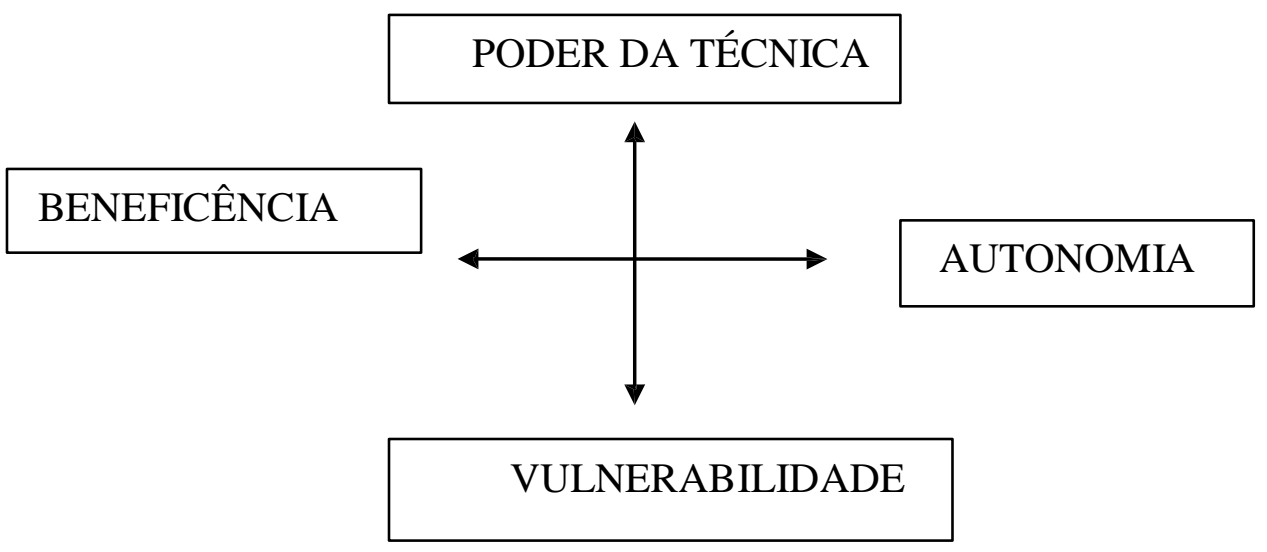

A tensão entre esses opostos é constante e saber para onde o pêndulo irá depende de como ocorre a relação médico/paciente; pesquisador/participante, no caso concreto, de acordo com variáveis que se instalam nessas relações e que precisam ser examinadas para além da simples capacidade civil dos envolvidos, ou nos dizeres bioéticos, sua autonomia.

E é nesse sentido que passarei a discorrer sobre os quatro vértices indicados, de modo a verificar como se dá a integridade da mencionada dinâmica. 
Para tanto, utilizarei do método dedutivo, partindo da análise de questões frequentemente postas ao exame do médico/pesquisador em sua relação com o paciente/participante e utilizando como marco inicial a bioética principialista de Beauchamp e Childress (2002) para confrontá-la com outros teóricos, em especial, Foucault e Feinberg, de modo a distinguir o paternalismo forte do paternalismo fraco e identificar aquele como pernicioso e prejudicial ao respeito pela autonomia do paciente/participante e este como necessário e suficiente apenas em casos pontuais e diante de necessidades principalmente transtitórias.

No capítulo 2, farei uma análise sobre o princípio da autonomia em uma visão bioética, no sentido do envolvimento das questões de vida e saúde e não com o viés patrimonialista fundante da capacidade civil posta no código normativo pertinente.

No capítulo seguinte, abordarei o princípio da beneficência, segundo pilar do quatérnio bioético.

No quarto capítulo, examinarei a vulnerabilidade enquanto princípio, para então analisar o poder da técnica de que o médico/pesquisador é detentor.

Ao final, tentarei formular uma solução para o conflito posto.

Concluída a introdução e expostos da primeira pessoa do singular os motivos ensejadores da pesquisa que ora se oferta, passo ao exame da questão posta, voltando para o uso da terceira pessoal do singular.

\section{O PRINCÍPIO DA AUTONOMIA: UM OLHAR PARA ALÉM DA CAPACIDADE CIVIL}

Como o próprio título do item está a indicar, não se pretende um olhar estanque sobre o elenco legal das capacidades civis, constantes dos arts. $3^{\circ}$ e $4^{\circ}$ do Código Civil e leis complementares pertinentes ao tema.

É que, examinar-se o agente capaz pelo critério da presunção absoluta da idade ou do discernimento para os atos da vida civil em geral, não resolve a questão posta de início.

Ou seja, o adulto ainda que sem limitações de natureza psíquica e/ou mental e, portanto, no gozo pleno de sua capacidade civil, pode ter sua autonomia reduzida em decorrência da vulnerabilidade a que exposto na vivência com a falta de higidez física, no que concerne a 
atos de natureza médica a que possa ser submetido e, também, em decorrência do poder da técnica de que é detentor uma das partes da relação - o médico/pesquisador.

Esclareça-se, de início, que o tema se desenvolve não somente em torno do ato médico em si, onde a relação se estabelece entre médico e paciente, mas, também, em derredor das pesquisas com seres humanos, em que a conexão examinada ocorre entre o pesquisador e o participante da pesquisa, neste texto chamado, simplesmente, de participante, como é cunhado pela Resolução 466/2012, do Conselho Nacional de Saúde que versa sobre o tema.

A incidência de uma patologia sobre o sujeito, seja ela de qualquer nível de gravidade, pode gerar para o momento, e em face de determinado ato, uma vulnerabilidade tal que reduza a habilidade da pessoa para a tomada de decisões concernentes à sua vida e saúde.

Diz-se aqui não importar o nível de gravidade, no sentido de que para preservar a justiça da avaliação que deve ser focada na realidade, não deve ser ela feita com base naquilo que se pensa tomando como parâmetro o -homem médioll, mas do indivíduo com suas peculiaridades, haja vista não ser a patologia em si, mas seu impacto sobre o indivíduo, variável de sujeito para sujeito, o que está posto em discussão.

Com efeito, o arcabouço pessoal de cada um, no viés emocional da formação de sua personalidade, gera diferentes consequencias, de indivíduo para indivíduo, em razão da intensidade da sintomatologia vivenciada.

Ao estudar as diversas personalidades, MILLON (2004) produziu um inventário de estilo de personalidades ${ }^{1}$ que tem sido aplicado em diversos estudos acadêmicos, de que é exemplo o de NOBRE (2011) ao examinar a influência da personalidade na percepção de dor aguda nos pacientes submetidos à cirurgia cardíaca.

Esses estudos corroboram a afirmação acima de que as características individuais do paciente/participante têm relevante impacto sobre como ele vivencia seu processo de adoecimento o que deve ser transposto, igualmente, para o sujeito de pesquisa clínica, em razão de sua posição de experimentadol;

\footnotetext{
1 O inventário abrange três áreas: Metas Motivacionais (busca entender como o sujeito se orienta a partir dos reforços apresentados pelo meio), Modos Cognitivos (procuram avaliar a forma de processamento de informação pelo indivíduo) e Relações Interpessoais (visam avaliar as relações do sujeito com os demais).
} 


\begin{abstract}
Quanto às características de personalidade, verificou-se que nos pacientes com menor expressão de dor os fatores Preservação e Individualismo, ambos relacionados à Meta Motivacional, e a Introversão ao Modo Cognitivo, propostos por Millon11, foram distintos significativamente; por sua vez, nos pacientes com maior expressão referida de dor, os estilos Proteção e Acomodação (Meta Motivacional), Extroversão e Afetividade (Modo Cognitivo), Retraimento, Discrepância, Comunicabilidade $e$ Firmeza (Relações Interpessoais). Os achados deste estudo mostram diferenças significativas na expressão de padrões de comportamento e estilos de personalidade dos pacientes estudados. (NOBRE, 2011, p.5)
\end{abstract}

Dito de outro modo, a vivência que cada pessoa tem em razão do impacto de uma doença é permeada pela sua visão personalíssima de quem se é, de como a patologia afeta sua vida, qual sua rede de apoio etc.

Assim, no próprio construir a autonomia em sentido bioético, já não podemos identificála, integralmente, com a capacidade civil, daí porque se dever pensar na autonomia como comparável a uma capacidade bioética e não capacidade civil, no sentido de que as questões referentes à vida e à saúde da pessoa devem ser por ela mesma decididas, mesmo quando ainda não atingida a maioridade civil. (AGUIAR, 2013)

Não obstante, ainda para aqueles que entendam como de aplicação absoluta os arts. $3^{\circ}$ e $4^{\mathrm{o}}$ do Código Civil mesmo para essas questões, percebe-se, atualmente, um movimento na direção da normatização da capacidade bioética quando, por exemplo, se verifica sua guarida legal ainda que sem a denominação ora dada.

Refira-se, exemplificativamente, ao novo Estatuto da pessoa com deficiência ou às normas do novo Código de Processo Civil ao tratar da interdição.

No estatuto, aparece em seu art. $6^{\circ}$, a possibilidade da pessoa com deficiência exercer direitos sexuais e reprodutivos e de conservar sua fertilidade, vedada a esterilização compulsória, direitos que dizem respeito, eminentemente, à saúde da pessoa.

E não deixa margens à dúvida quanto ao alcance de sua aplicação às pessoas com deficiência mental, quando, ao definir deficiência em seu art. $2^{\circ}$, esclarece considerar-se como tal aquela pessoa que tenha impedimento de longo prazo de natureza física, mental, intelectual ou sensorial (sem negrito no texto original).

É imperioso acrescentar que, embora não expressamente, o novo Código de Processo Civil não deixa de amparar a capacidade bioética do interdito ao estabelecer em seu art. 755, II que na sentença que decretar a interdição, o juiz considerará as características pessoais do interdito, observando suas potencialidades, habilidades, vontades e preferências.

Ao comentar essa norma, DIDIER JR. (2015, p. 1743), um dos idealizadores do novel código, aponta um processo de humanização que se pretendeu incorporar à ação de interdição. 
Nada impede, e, aliás, recomenda, que dentre essas vontades e preferências o Juiz faça inscrever as diretivas antecipadas de vontade do interditando, nos termos da resolução CFM 1995/2012 que trata sobre o tema, reverenciando assim a autonomia do paciente naquilo em que pode ele se autodeterminar.

A capacidade bioética encontra-se, deste modo, ao meu sentir, albergada pelo ordenamento positivo, apesar de não expressamente referida como tal, não se confundindo com a capacidade civil, a qual deve ser limitada, primordialmente, às questões de natureza patrimonial.

Esse fenômeno de proteção legal sem a indicação de um nomen júris não é estranho ao

\section{Direito.}

Ao contrário, na esteira do que BOBBIO (1993) denomina a historicidade dos direitos, estes somente surgem quando se torna necessário proteger algum novo bem jurídico.

Assim, já houve hipótese de ser a intimidade genética garantida, ainda quando dela não versava, de modo explícito, o ordenamento positivo, como aconteceu no julgamento pelo Supremo Tribunal Federal, em 1994, do Habeas Corpus 71373•4/RS. O caso discutia a possibilidade ou não de conduzir-se sob vara famoso jogador de futebol para a realização de exame de DNA em ação de investigação de paternidade.

O voto vencedor, proferido pelo Ministro Marco Aurélio de Melo, ao assegurar que o réu tinha o direito de não ser conduzido sob vara para a coleta do material necessário à realização do exame, embora tenha fundamentado tal direito no princípio da dignidade humana, na verdade, pretendeu assegurar a intimidade genética. (AGUIAR, 2007)

Põe-se, assim, de relevo, que a autonomia no exame das questões de saúde e vida, deve ser alargada, ultrapassando o conceito da capacidade civil.

\section{O PRINCÍPIO DA BENEFICÊNCIA}

Ao introduzirem o princípio da beneficência no rol de princípios bioéticos, BEAUCHAMP e CHILDRESS (2002, p.282) apontam-no como se referindo -à obrigação moral de agir em benefício de outros $\|$.

Aduzem, ademais, que a beneficência diria respeito não somente à chamada beneficência positiva, aquela que visa à -propriciaçãoll de benefícios, mas, também, à utilidade, a qual 
requer sejam ponderados os benefícios e as desvantagens, o que, embora chegue próximo do princípio da não maleficência, com este não se confunde, como eles mesmo explicitam:

-O termo _não maleficência' é às vezes usado em sentido amplo, incluindo a prevenção de danos e a eliminação de condições prejudiciais. Contudo, a prevenção e a eliminação requerem atos positivos de beneficiar outros, pertencendo, portanto, antes à beneficência que à não-maleficência.॥ (p.281)

$\mathrm{Na}$ atualidade, tem-se contato com essa proximidade entre a beneficência e não maleficência, por exemplo, quando se depara com a notícia de que o estado do Rio Grande do Sul, ciente de pesquisas realizadas por uma organização argentina, suspendeu o uso, na água potável, de pyriproxifen, produto utilizado no combate ao mosquito Aedes aegypti, pelos riscos apontados, por pesquisadores argentinos, da possibilidade de a substância potencializar a má-formação cerebral supostamente causada pelo vírus da zika.

Apesar de o Ministério da Saúde Brasileiro informar que não existe nenhum estudo epidemiológico que comprove a associação do uso de pyriproxifen e a microcefalia, a mera existência de risco levou à suspensão do uso da substância.

Ou seja, o possível malefício causado pelo uso do larvicida foi considerado de maior relevância do que os supostos benefícios dele derivados.

$\mathrm{Na}$ visão dos autores referidos, o princípio da beneficência se refere à obrigação moral de agir em benefício de outros. (p.382)

\section{A VULNERABILIDADE}

A vulnerabilidade surge como princípio bioético desde os primórdios da disciplina, embora não haja sido expressamente formulada pela bioética principialista de BEAUCHAMP e CHILDRESS.

É que esses pioneiros, ao tratarem da autonomia, falam das dificuldades pelas quais cada pessoa passa ao estabelecer decisões autônomas incluindo a inabilidade para entender as informações e expressar uma preferência, o que diria respeito à vulnerabilidade cognitivosocial, sem, entretanto, nominá-la.

Reconhece-se, não obstante, que foi durante a segunda metade da década de '90 do século passado que o tema ganhou maior relevo dentro da bioética, discussões que culminaram no reconhecimento formal da vulnerabilidade enquanto princípio, em 1998, na Declaração de Barcelona. Nesse documento europeu, a vulnerabilidade aparece pela primeira 
vez considerada como princípio bioético básico, ao lado da autonomia, dignidade e integridade.

Em sua formulação original, o documento ressalta que esse princípio expressa a condição de todos as vidas, humanas ou não humanas, serem possíveis de serem feridas. Impõe, ainda, que a idéia da proteção da vulnerabilidade pode criar uma ponte entre estranhos morais em uma sociedade pluralista, devendo ser o respeito pelos vulneráveis essencial para a formulação de políticas no estado de bem-estar moderno. ${ }^{\text {ii }}$

Em 2005, a vulnerabilidade, enquanto princípio, passa a fazer parte de um documento supranacional.

A Declaração Universal sobre Bioética e Direitos Humanos, da UNESCO, em 2005, o reconhece, em seu art. $8^{\circ}$ ao proclamar que na aplicação e no avanço dos conhecimentos científicos, da prática médica e das tecnologias que lhes estão associadas, deve ser tomada em consideração a vulnerabilidade humana.

E mais ainda, no que interessa de perto a este trabalho, indica que os indivíduos e grupos particularmente vulneráveis devem ser protegidos, e deve ser respeitada a integridade pessoal dos indivíduos em causa.

É exatamente o espectro dessa proteção que não deve desbordar para um paternalismo que fira, mortalmente, a autonomia do sujeito.

Ao tratar da vulnerabilidade, NEVES (2006) aponta três sentidos diferentes pelos quais ela pode ser vista: como princípio, condição e característica.

Enquanto princípio, afirma a autora que a vulnerabilidade -obriga, na sua acepção mais comum de característica particular, à proteção adequada dessa fragilidade acrescida, numa ação positiva que varia de acordo com as necessidades específicasll; (NEVES, 2006, p.169)

Para que a proteção seja adequada, ela deve se basear numa ação positiva que leve ao empoderamento do sujeito e não à substituição de sua vontade pela expertise do médico.

Exemplo claro dessas necessidades específicas ocorre, como afirma COSTA (2014, p.99), nos casos em que a pessoa encontra-se em decorrência do uso de entorpecentes com habitualidade, impossibilitada, ainda que temporariamente, de agir com discernimento. Nesses casos, a possibilidade de intervenção deve se limitar ao grau mínimo necessário para que o indivíduo possa voltar a tomar decisões autônomas.

\footnotetext{
ii Declaração de Barcelona. 1988. Item 4.
} 
Esse é um claro exemplo de paternalismo fraco.

Com efeito, como assevera DWORKIN (1978. p. 262/3), a imposição de uma concepção específica do que seja a beneficência, ainda que por parte de médicos, tem como conseqüência a negação do respeito pela autonomia mesmo que o decisor pense estar realmente fazendo um bem e até possa ter concepções técnicas melhores do que aquela sobre quem se decide.

\section{O PODER DO CONHECIMENTO TÉCNICO}

Ao final, deve-se encarar a ultima ponta do quatérnio bioético: o poder técnico do médico/pesquisador.

É conhecida a crítica feita por Foucault (1979.p.97) à onipotência da ciência médica no âmbito do que chamou de -medicalização autoritária de corpos e doenças\|:

-O controle da sociedade sobre os indivíduos não se opera simplesmente pela consciência ou pela ideologia, mas começa no corpo, com o corpo. Foi no biológico, no somático, no corporal que, antes de tudo, investiu a sociedade capitalista. O corpo é uma realidade bio-política. A medicina é uma estratégia bio-politica. II

Ressalta Foucault que o controle médico afeta, mais profundamente, a população mais pobre, o que reforça a tese acima exposta de que quanto mais vulnerável, no caso foucaultiano, vulnerabilidade econômica e social, maior deveria ser o cuidado do médico/pesquisador para resguardar a autonomia do paciente/participante.

Ao examinar essa microfísica do poder foucaultiano, indaga MARTINS ( 2004 ) sobre qual fronteira pode haver entre o ideal de saúde preconizado pela Medicina, -alienante e submisso ao poder médico, e algo da ordem da saúde, não ideal, mas efetiva, vinculado à potência singular da pessoa?

E, assim, coloca a grande questão atualmente desvelada pelos estudiosos da bioética sobre como esquadrinhar a autonomia do paciente/participante. Ou, se -a autonomia dos indivíduos na coletividade estaria recuperada simplesmente por uma "resistência" — ou reação - às imposições de uma Medicina oficial científica? (MARTINS, 2004, p. 2) 


\section{A TÍTULO DE SOLUÇÃO DOS CONFLITOS POSTOS}

Um olhar para a história sob a ótica dos arquétipos traz-nos uma ampliação fantástica sobre os motivos que nos levam, desde Déscartes, a separar o objetivo do subjetivo, a ciência da religião, os conhecimentos técnicos da Medicina dos conhecimentos tradicionais etc.

Conforme nos ensina BYINGTON (2008, p.277), o conhecimento dialético introvertido desenvolvido nos monastérios durante séculos, extroverteu para o mundo pelas universidades, em um viés objetivo, transformando-se no chamado método experimental.

Daí, surgiu, em sincronicidade, a descoberta daquela que teria sido a maior das heresias - o sistema heliocêntrico.

Ao descobrir, em 1543, que não era o Sol que girava em redor da Terra, mas o inverso, Copérnico inaugura as ciências modernas.

Mas foi Galileu que, ao referendar o heliocentrismo, tornou-se o maior cientista perseguido pela Igreja, a qual ainda sustentava o sistema ptolomeico inverso de ser a Terra o centro do Universo.

Foi exatamente a condenação de Galileu à prisão domiciliar que sacramentou a separação da Igreja e da ciência, selando a ruptura entre as ciências modernas e a instituição religiosa.

Esta dissociação encontra-se na base dos conflitos entre a ciência e a religião, bem assim, certamente, na base dos que consideram como um conhecimento inválido todo aquele não produzido pela ciência.

A Medicina, presa ao juramento de Hipócrates tem manejado seu saber, a título de proteger os pacientes utilizando um paternalismo forte.

Tome-se, como exemplo, dentre outros, a resolução do Conselho Federal de Medicina $n^{\circ} 1.021 / 80$, que versa sobre o tratamento que deve ser dado ao paciente testemunha de Jeová que se recuse a receber sangue de outrem.

No parecer CFM 21/80, que culminou com a edição da norma administrativa mencionada, o Conselheiro Relator inicia por apontar a recusa dos adeptos da Testemunha de Jeová em permitir a transfusão sangüínea como problema criado para o médico. (sem grifo no original): -O problema criado, para o médico, pela recusa dos adeptos da Testemunha de Jeová em permitir a transfusão sangüínea, deverá ser encarada sob duas circunstâncias\| 
Ou seja, autodeterminar-se quanto ao tratamento que deseja receber é visto não como um direito do paciente, mas como um obstáculo à prática do ato médico, certamente em razão do preconceito arraigado de que a recusa decorre de dogma religioso que deve ser visto como desafiador do conhecimento científico de que o médico se diz detentor.

Na mesma linha, pode-se apontar, igualmente, como exemplo do paternalismo forte ou radical a decisão do médico de realizar ou não cirurgia de transgenitalização do transexual -verdadeiroll.

Com efeito, consoante se lê da PORTARIA N ${ }^{\circ}$ 2.803, DE 19 DE NOVEMBRO DE 2013(*) que redefine e amplia o Processo Transexualizador no Sistema Único de Saúde (SUS) e da Resolução no 1955/2010, do Conselho Federal de Medicina (CFM), não tem o paciente assegurada sua autonomia para decidir sobre seu corpo, havendo expressa menção, neste último documento, ao poder do médico em respeitar ou não essa autonomia:

Art. $4^{\circ}$ Que a seleção dos pacientes para cirurgia de transgenitalismo obedecerá a avaliação de equipe multidisciplinar constituída por médico psiquiatra, cirurgião, endocrinologista, psicólogo e assistente social, obedecendo os critérios a seguir definidos, após, no mínimo, dois anos de acompanhamento conjunto:

1) Diagnóstico médico de transgenitalismo;

2) Maior de 21 (vinte e um) nos;

3) Ausência de características físicas inapropriadas para a cirurgia.

Ressalte-se, inclusive, que essa resolução do CFM revogou a de $\mathrm{n}^{\circ}$ 1652/02 mas manteve, integral e fielmente, o art. $4^{\circ}$ da anterior, realçando o viés do domínio da técnica em nível opressor sobre o paciente transexual, cuja vontade fica anulada.

Oportuno transcrever a opinião sobre o tema, ofertada por GRANT (2015, p.106)

Caberá, portanto, à equipe multidisciplinar constituída por médico psiquiatra, cirurgião, endocrinologista, psicólogo e assistente social selecionar os possíveis candidatos à cirurgia transgenitalização, de acordo com os critérios estabelecidos no art. $3^{o}$, e, obedecendo aos requisitos instituídos no art. $4^{o}$, após, no mínimo, dois anos de acompanhamento conjunto, decidir pela sua realização ou não em cada caso.

Ou seja, a autonomia do paciente é posta à prova, mais uma vez, diante do entendimento de que não é ele quem sabe o que é melhor para si, mas sim os especialistas que o atendem, como se não se tivesse direito ao próprio corpo, apesar das regras normativas que protegem, formalmente, este direito, de que são exemplos os arts.13 e 14 do Código Civil.

Neste diapasão, oportuno mencionar a visão de SPIVAK (2010) no sentido de que, ao se colocar como titular do poder da técnica, o médico supõe ser o paciente um subalterno a quem não é dado falar. O escrito de Spivak leva-nos a esse lugar de reflexão para um olhar 
amplificativo do tema abordado para concluir pela redução ou anulação da vontade do outro, em razão de uma superioridade decorrente do saber técnico.

O paternalismo forte ou radical, consoante nos ensina FEINBERG (1986, p.14), é injustificável porque é degradante e inconsistente com a autonomia pessoal entendida como soberania pessoal.

Ao explicar o paternalismo radical ou forte de Feinberg, Beauchamp e Childress ressaltam:

-Um partidário do paternalismo forte se recusa a consentir com os desejos, as escolhas e as ações autônomas de uma pessoa a fim de protegê-la, com freqüência restringindo a informação disponível e passando por cima de escolhas informadas e voluntáriasl. (202, p. 302)

Garantir possa esse quatérnio funcionar de modo harmonioso passa pela aceitação do paradigma da alteridade enquanto valor do respeito pelo outro, na medida em que falar de alteridade é compreender o outro, colocando-se, empaticamente, em seu lugar, e, não em uma posição de superioridade e poder.

\section{CONCLUSÃO}

Autonomia, beneficência, vulnerabilidade e técnica formam vértices do quatérnio bioético, o qual deve ser mantido sempre em ponto de equilíbrio para assegurar o respeito pela autonomia do paciente/participante e garantir que o poder da técnica não a anule em nome de um paternalismo radical.

Tal ponto de equilíbrio somente se atinge na análise do caso concreto, haja vista que a vulnerabilidade e a autonomia são princípios que devem ter seu exame realizado em caráter personalíssimo.

Não são as características do -homem médio que devem ser adotadas na relação médico paciente na avaliação das ações práticas a serem tomadas pelos médicos, o mesmo se aplicando aos pesquisadores diante dos participantes de pesquisa, haja vista as diferenças fundamentais da formação de personalidade dos indivíduos.

A técnica não deve impactar nas escolhas médicas em função da vulnerabilidade do paciente, seja pela sua patologia, condição econômica, social ou cognitiva, sob pena de exercer-se indevido paternalismo forte que subtraia do indivíduo sua autonomia. 
Para as decisões que envolvam a saúde e vida dos pacientes/participantes deve-se atentar para a autonomia vista pelo viés da capacidade bioética, afastada da capacidade civil, a qual deve ficar restrita, preferencialmente, às questões de natureza patrimonial.

São autônomos para as questões envolvendo decisões a respeito da vida e da saúde as pessoas portadores de deficiência, inclusive mental, conforme reconhecido pelo Estatuto da Pessoa com Deficiência.

Quanto mais grave a vulnerabilidade, maior o dever do médico/pesquisador em preservar a autonomia do paciente/participante, garantia esta que deve se realizar de modo a alcançar o outro em uma vivência de alteridade de forma a que seu consentimento/autorização se dê o mais autonomamente possível.

Refere-se como alteridade, ao paradigma pelo qual nas relações estabelecidas entre as pessoas, elas permitam se colocar no lugar do outro, não para decidir por ele, mas para empatizar e deste modo respeitar as diferenças existentes entre os indivíduos.

\section{REFERÊNCIAS}

AGUIAR, Mônica. Para além da capacidade: o impacto da vulnerabilidade em matéria de autonomia em questões de saúde.Revista Brasileira de Bioética. Volume 9 - Suplemento 2013

AGUIAR, Mônica . Direito à intimidade genética em face do art.232 do código civil e sua defesa pela criação de um habeas genoma. Evocati Revista , v. 22, p. 1-20, 2007.

BEAUCHAMP, Tom.L; CHILDRESS, James F. Princípios de Ética Biomédica. Trad.: Luciana Pudenzi. São Paulo: Loyola. 2002.

BOBBIO, Norberto. Teoria Generale Del Diritto. Milão: G.Giappichelli Editore. 1993. BRASIL Código civil (2002)2.ed São Paulo:Saraiva, 2005

BRASIL. Lei $\mathbf{n}^{\mathbf{0}}$ 13.146, de 6 de julho de 2015. Institui a Lei Brasileira de Inclusão da Pessoa com Deficiência (Estatuto da Pessoa com Deficiência).

. CONSELHO FEDERAL DE MEDICINA. RESOLUÇÃO 1.021/80. Publicada no D.O.U.(Seção I - Parte II) de 22/10/80.

. CONSELHO FEDERAL DE MEDICINA. RESOLUÇÃO CFM nº 1.955/2010. (Publicada no D.O.U. de 3 de setembro de 2010, Seção I, p. 109-10). Dispõe sobre a cirurgia de transgenitalismo e revoga a Resolução CFM n ${ }^{\circ}$ 1.652/02. (Publicada no Diário Oficial da União; Poder Executivo, Brasília-DF, n. 232, 2 dez.2002. Seção 1, p.80/81)

.CONSELHO FEDERAL DE MEDICINA. RESOLUÇÃO CFM nº 1.995/2012

Revista de Biodireito e Direitos dos Animais | e-ISSN: 2525-9695| Brasília | v. 2 | n. 1 | p. 70 - 85 | Jan/Jun. 2016. 
(Publicada no D.O.U. de 31 de agosto de 2012, Seção I, p.269-70). Dispõe sobre as diretivas antecipadas de vontade dos pacientes.

.CONSELHO NACIONAL DE SAÚDE. RESOLUÇÃO 466, DE 12 DE DEZEMBRO DE 2012. Publicada no DOU no 12 - quinta-feira, 13 de junho de 2013 Seção 1 - Página 59. Dispõe sobre diretrizes e normas regulamentadoras de pesquisa envolvendo seres humanos.

- SiSTEMA ÚNICO DE SAÚdE. PORTARIA 2.803, DE 19 DE NOVEMBRO DE 2013. Redefine e amplia o Processo Transexualizador no Sistema Único de Saúde (SUS).

BYINGTON, Carlos Amadeu Botelho. Psicologia Simbólica Junguiana. A viagem de humanização do cosmos em busca da iluminação. São Paulo: Linear B, 2008.

BYINGTON, Revisitando o Método de René Descartes pelo Método Simbólico de Carlos Byington, para o estudo do Self Familiar e do feminino. Palestra - Simpósio Núcleo de Estudos Junguianos, PUC-SP, 2015

COSTA, Jessica Hind Ribeiro. A internação compulsória no âmbito das cracolândias: implicações bioéticas acerca da autonomia do dependente químico. [manuscrito] / Jessica Hind Ribeiro Costa. - Dissertação (mestrado) - Programa de Pós-Graduação em Direito da Universidade Federal da Bahia. Salvador, 2015.

DECLARAÇÃO DE BARCELONA. $1988 . \quad$ Disponível em: http://www.cnpcjr.pt/downloads/Declara\%E7\%E3o\%20de\%20Barcelona.pdf. Acesso em 08 abr.2016.

DESCARTES, René. Discours de La méthode - Pour bien conduire La raison ET chercher La verité dans les sciences. In Descartes, Oeuvres et letters. Paris: Bibliotheque de la Pleiade, Gallimard. 1953.

DANTAS, Bruno; TALAMINI, Eduardo; DIDIER JR., Fredie; WAMBIER, Teresa Arruda Alvim. Breves Comentários ao Código de Processo Civil. São Paulo: Revista dos Tribunais. 2015 .

DWORKIN, Ronald. Taking rights seriously. Cambridge: Harvard University Press. 1978. FEINBERG, Joel. Harm to self. Oxford: Oxford University Press, 1986

FOUCAUlT, M. O nascimento da Medicina Social. Microfísica do poder. Tradução Roberto Machado. Rio de Janeiro: Graal, 1979.

GRANT, Carolina. Direito, bioética e transexualidade: um estudo sobre os limites e as possibilidades de ampliação da tutela jurídica das experiências trans*.2015. $223 \mathrm{f}$. 
MARTINS, André. Biopolítica: o poder médico e a autonomia do paciente em uma nova concepção de saúde. Interface (Botucatu), Botucatu , v. 8, n. 14, p. 21-32, Feb. 2004 . Available from <http://www.scielo.br/scielo.php?script=sci_arttext\&pid=S141432832004000100003\&lng=en\&nrm=iso $>$ access on 27 Mar. 2016. http://dx.doi.org/10.1590/S1414-32832004000100003.

MILLON, Theodore. Millon Index of personality styles-Revised manual, Minneapolis: Pearson Assessments. 2004.

MOREIRA, Mayana Sales. Testamento Vital: uma análise da extensão de sua eficácia às situações diversas da terminalidade de vida. Salvador, 2015. 129 p. Dissertação (Mestrado em Direito) - Programa de Pós-Graduação em Direito - PPGD. Universidade Federal da Bahia. 2015 .

NEVES, M. Patrão. Sentidos da vulnerabilidade: característica, condição, princípio. Revista Brasileira de Bioética. Volume 2 - Número 2- 2006

NOBRE, Thaiza Teixeira Xavier et al . Aspectos da personalidade e sua influência na percepção da dor aguda em pacientes submetidos à cirurgia cardíaca. J. bras. psiquiatr., Rio de Janeiro , v. 60, n. 2, p. 86-90, 2011 . Available from $<$ http://www.scielo.br/scielo.php?script=sci_arttext\&pid=S004720852011000200003\&lng=en\&nrm=iso>. access on $30 \quad$ Mar. 2016. http://dx.doi.org/10.1590/S0047-20852011000200003.

OLIVEIRA, Sérgio de Freitas. As vozes presentes no texto acadêmico e a explicitação da autoria. In Pedagogia em ação. V.6 (n.1) 2014. 